\title{
Entre deuses e um deus: a vivência da fé nos personagens de Hibisco Roxo, de Chimamanda Ngozi Adichie
}

http://lattes.cnpq.br/4206101271130707

\author{
Francisco Célio da Silva Santiago ${ }^{2}$
}

http://lattes.cnpq.br/6772073064013301

Enviado em: 05/09/2018

Aceito em: 17/01/2019

\begin{abstract}
RESUMO: O presente trabalho objetiva uma análise dos elementos religiosos que norteiam e servem como mecanismos temporais no romance Hibisco Roxo (2011), da nigeriana Chimamanda Ngozi Adichie. Publicado em 2003, o primeiro romance da autora aborda um núcleo familiar permeado pela violência doméstica que utiliza do pretexto religioso como uma das maneiras de infligir agressões. O personagem Eugene, tenta seguir com rigor os preceitos católicos e a cultura inglesa, e quando seus familiares não os executam com perfeição, provoca uma ira em si e opta em violentálos com agressões físicas. Em contrapartida, há o seu pai, Papa-Nnukwu, um ancião tradicionalista que não permite ter seus costumes igbos interferidos; e Tia Ifeoma que consegue transitar pelas duas religiões - tradicional e católica - e extrair o que de melhor elas podem oferecer. Utilizaremos os estudos de Hall (2003), Bonnici (2009), Said (2007) sobre o choque cultural de culturas diferentes e a imposição da metrópole sobre a colônia, visto que a Nigéria foi por muito tempo colônia inglesa. Sobre o elemento das aparições de Nossa Senhora na narrativa, utilizaremos as ideias de Clodovis M. Boff (2006) sobre o papel de Maria como elemento nacional e suas aparições como fomentadora da religiosidade popular.
\end{abstract}

PALAVRAS-CHAVE: Hibisco Roxo. Chimamanda Ngozi Adichie. Intolerância religiosa. Violência doméstica.

\begin{abstract}
The present work's purpose is to analyze the religious elements that guide and serve as temporal mechanisms in the novel Hibisco Roxo(2011), by Nigerian author Chimamanda Ngozi Adichie. Published in 2003, her first romance deals with a household permeated by domestic violence that uses the religious excuse as one of the ways to inflict aggressions. The character Eugene tries to wholeheartedly follow both the catholic norms and the English culture and when his kin do not fulfill them perfectly, it enrages him and so he chooses to violate them with physical aggression. In contrast, his father, Papa-Nnukwu, is a traditionalist elder that does not allow that his igbo customs to be interfered with; and aunt Ifeoma can meander through both religions - traditional and Catholic - and extract the best they can offer her. We will use the studies of Hall (2003), Bonnici (2009), Said (2007), about the cultural shock of different cultures and the imposition of a metropolis on the colony, as Nigeria was for a long time an English colony. About the element of apparition of Our Lady in the narrative, we use the ideas of Clodovis M. Boff (2006) on the role of Mary, as a national element and her apparitions as an instigator of popular religiousness.
\end{abstract}

\footnotetext{
${ }^{1}$ Mestrado em andamento em Letras, na Universidade Federal do Ceará, UFC, Brasil. E-mail: marianaasc92@,hotmail.com

${ }^{2}$ Mestre em Computação Aplicada (Informática educativa). Professor voluntário do Instituto Federal do Ceará - IFCE - Campus Tianguá, avaliador MEC/INEP de cursos superiores e ouvidor da Faculdade Católica da Ibiapaba. E-mail: celiosantiago@yahoo.com.br
} 
KEY WORDS: Purple hibiscos. Chimamanda Ngozi Adichie. Religious intolerance. Domestic violence.

\section{INTRODUÇÃO}

Como muitos países colonizados, a Nigéria sofreu interferências ocidentais no modo como seus indivíduos viviam sua religiosidade. Primeiro que o espaço territorial delimitado para constituir muitos países africanos, foi decidido de maneira aleatória em uma reunião de primeiros-ministros, a Conferência de Berlim (1885), que dividiu entre grandes potências europeias os territórios da África. Sem importar com as etnias que lá viviam, grupos rivais acabaram sendo aglutinados em um território. Como instituição parceira, a Igreja Católica tinha uma função preponderante: a civilização das colônias africanas, pois nas orientações eclesiásticas da época, para evangelizar antes era necessário civilizar. Como a Conferência de Berlim deu total apoio e garantias para as implantações de missões nos países dominados, a Igreja Católica alegava que precisava de vultosas verbas financeiras para manter seus missionários nas colônias.

$\mathrm{Na}$ Nigéria, maior país africano em população, estão presentes várias etnias com um forte passado de rivalidade, como os igbos, haussás, fulanis, iorubás ${ }^{3}$, cada qual com sua religião, preceitos, que acabaram tendo que se subjugar às religiões muçulmana, católica e protestante. O Pós-colonialismo - corrente sociológica, política e literária - surgido após a independência dos países africanos, mesmo sendo um termo ainda controverso entre os estudiosos, é ligado a produção epistemológica crítica à cultura dominante do colonizador. O eurocentrismo que tanto permeia o mundo global é criticado em diversos movimentos literários, como o Modernismo, no Brasil, Neo-barroco, na América Latina, e, o então, Póscolonialismo, em sua maioria com escritores africanos. Um lócus que por muito tempo foi narrado a partir do europeu, agora é um lugar de enunciado em que seu próprio povo narra a partir das suas experiências coloniais. Chimamanda Ngozi Adichie, escritora nigeriana, faz parte do grupo contemporâneo de destaque que vem criando narrativa com fortes críticas à sociedade pós-colonial. Discípula do grande romancista nigeriano Chinua Achebe, a escritora, com então três romances publicados, já versou sobre a Guerra do Biafra, a imigração para países desenvolvidos e o período ditatorial na Nigéria. Em paralelo a esses episódios históricos da nação nigeriana, a natureza humana também é narrada, como em Hibisco Roxo (2011), seu primeiro romance publicado em 2003 nos Estados Unidos. A protagonista Kambili tem suas turbulentas relações familiares permeadas pela figura autoritária do seu pai Eugene Achike. Uma das formas de opressão que o pai utiliza é a religião católica, através de práticas de suplícios, de constantes vigilâncias sobre a conduta e sexualidade dos filhos.

É perceptível que autora utiliza do elemento religião para desenvolver críticas a respeito da sociedade pós-colonial. Existe o personagem Eugene/Papa que, mesmo sendo igbo, rejeita sua cultura tradicional e aceita apenas a espiritualidade cristã católica como soberana. Por conta dessa fé cega, ele utiliza suplícios em seus familiares. Ele sofre do "complexo de Próspero4", como Shohat e Stam (2006) nomeiam os colonizados que possuem uma

\footnotetext{
3 "Nos 923.768 km² que compõem o país vivem mais de 150 milhões de habitantes, pertencentes a três grandes etnias [...] e dezenas de grupos minoritários" (REIS, 2011, p. 26). Chimamanda Ngozi Adichie pertence a etnia igbo e seus personagens do romance em questão deste artigo, também.

${ }^{4}$ Próspero é um personagem da peça A Tempestade (1623), de Shakespeare. A peça é tida, nos Estudos Culturais, como
} 
dependência à figura do branco. Papa-Nnukwu é um senhor idoso, pai de Eugene. Ele é resistente às mudanças impostas pela cultura inglesa e continua seguindo a espiritualidade dos seus antepassados. É categorizado pelo filho como ímpio, pagão, adorador do demônio. Já Tía Ifeoma, irmã de Eugene, é a personagem sincrética. Ela professa duas religiões: a do pai e a católica. Ela transita no entrelugar. Esse meio termo produz "O novo" (BHABHA, 1998) que ao mesmo tempo que é uma novidade em relação ao passado, é também um ato de resistência, mexendo nas estruturas de poder,

A narrativa é dividida em quatro momentos temporais: 1. Quebrando os Deuses Domingo de Ramos, 2. Falando com nossos espíritos - Antes do Domingo de Ramos, 3. Os pedaços de Deuses - Após o Domingo de Ramos e 4. Um Silêncio Diferente - O presente.

\section{QUEBRANDO OS DEUSES - DOMINGO DE RAMOS}

$\mathrm{Na}$ primeira parte da narrativa, o livro já se inicia in media res, com Kambili narrando que seu irmão não havia comungado, "As coisas começaram a se deteriorar lá em casa quando meu irmão, Jaja, não recebeu a comunhão, e Papa atirou seu pesado missal em cima dele e quebrou as estatuetas da estante" (ADICHIE, 2013, p. 095). A partir da primeira frase já encontramos o tom da narrativa: conservadorismo religioso e violência doméstica. As missas são os lugares preferidos para Eugene ostentar sua grande civilidade cristã. É o primeiro que comunga e toma para si a função de observar quem não o faz, sempre informando para o padre o nome do indivíduo depois da missa. Por isso a ausência do filho enfureceu-o tanto. O pároco o estima muito e sempre cita o comportamento exemplar de Eugene nas homilias. Padre Benedict é um branco inglês e uma das modificações que fez na paróquia, assim que tomou posse, foi diminuir o número de palmas e canções em línguas nativas demonstrando desconhecimento das orientações do recente Concílio Vaticano II. Logo, Eugene nutria admiração pelo padre e não cansava de fazer doações generosas para os pedidos do sacerdote.

Na obra Orientalismo (1978), o autor Edward Said traça a genealogia de como o europeu criou a contraposição ao Ocidente. O Oriente e terras abaixo da linha do Equador são a antítese de civilidade dos ocidentais, portando subjugá-los, através do pretexto de civilizálos, outorgou a pilhagem, a escravidão, o genocídio e o apagamento cultural dos povos. "O orientalista moderno se considerava um herói resgatando o Oriente da obscuridade, alienação e estranheza que ele próprio cuidara de identificar”" (SAID, 2011, p. 176).

A religião foi uma das esferas de combate. A imposição da religiosidade de base cristã, tida como a verdadeira e única crença, foi uma das práticas dos colonizadores. Partindo do pressuposto que os nativos eram seres infantilizados e vivendo em estado de selvageria, o europeu, em seu máximo poder, impôs sua cultura. "Dominada por uma raça que os conhece e sabe o que é bom para eles mais e melhor do que poderiam possivelmente saber eles próprios" (SAID, 2007, p. 66).

uma alegoria do processo de colonização e tratamento aos nativos das terras tomadas. Próspero, fugindo da sua terra onde foi jurado de morte, chaga a uma ilha sem localização certa, e passa a se autodedominar dono. Expulsa Sícorax, vista como bruxa, e torna o filho, Calibã, como seu escravo. Nessa relação de servidão, Calibã terá por obrigação aprender a língua e os costumes do seu senhor.

5 A partir desta citação, as demais referentes a obra Hibisco Roxo, de Chimamanda Ngozi Adichie, serão citadas apenas pelo número da página. 
Tendo Eugene uma origem em uma comunidade de igbos que praticavam a religião tradicional, ainda menino, é entregue por seus pais para os padres católicos ingleses, afim de obter educação. Ao passo que é doutrinado através da educação eurocêntrica, Eugene desenvolve aversão as práticas culturais do seu povo e renega seus familiares, principalmente seu pai, um senhor que não se permitiu ter sua cultura interferida. A propagação dos ideais eurocêntricos se deu com grande sucesso através de instituições de ensino, muitas administradas por religiosos que "assumiram a missão civilizadora europeia" (REIS, 2011, p. 23). Outrora organizadas através da transmissão oral de conhecimentos através dos anciãos, as crianças africanas passaram a frequentar escolas que as doutrinavam em uma cultura diferente da delas, inclusive utilizando a língua do colonizador e sendo catequisadas na religião dos brancos, considerada superior.

Ano depois, Eugene se torna um grande empresário, dono de um jornal opositor ao governo e um filantropo muito generoso. Socialmente é visto como um grande homem, todavia só sua família conhece o quão paradoxo é. Utilizando da violência doméstica e do terror psicológico, ele domina seus filhos e esposa. Em relação ao seu pai, renega-o, impedindo até que os filhos tenham contato com o avô. "Meu pai desperdiçava seu tempo adorando deuses de madeira e pedra. Eu não seria nada hoje se não fosse pelos padres e pelas irmãs da missão" (p.53).

Essa gratidão/ingratidão é o que permeia a vida de Eugene. Em alguns episódios descritos por Kambili, visualizamos o quanto seu pai esforça-se em aparentar uma impecável família cristã, um inglês sem sotaque, ou seja, sua preocupação é sempre em se enquadrar nos parâmetros ocidentais.

Papa mudou de sotaque quando respondeu, adotando uma pronúncia britânica, como fazia quando falava com o padre Benedict. Ele se mostrou gracioso e ansioso por agradar, como sempre era com os religiosos, principalmente os religiosos brancos. (p. 52)

- Kambili e Jaja, hoje à tarde vocês irão à casa de seu avô visitá-lo. Kevin vai levá-los. Lembrem, não comam nada nem bebam nada. E, como sempre, vão ficar só quinze minutos. Quinze minutos. [...] Papa jamais cumprimentava Papa-Nnukwu, jamais o visitava, mas mandava maços de nairas para ele por intermédio de Kevin ou de um dos membros da umunna. (p. 68-69)

Fanon aborda a preocupação do negro colonizado em se assemelhar com o branco. $\mathrm{O}$ ato de falar bem a língua do colonizador lhe garante um status de civilidade, "possuir a morfologia de tal e qual língua, mas é sobretudo assumir uma cultura, suportar o peso de uma civilização" (FANON, 2008, p. 33).

Eugene, como em muitos lares cristãos, faz preces antes das refeições. Ele até mesmo inventou um novo nome para a Virgem Maria: Nossa Senhora Amparo do Povo Nigeriano. Interessante que ao mesmo tempo que ele vangloria tudo que é ocidental, ele cria uma Maria nigeriana. Talvez não negra, pois seria demais para nosso personagem tão autorracista, mas uma Maria com identidade próxima a dele. Boff (2009) argumenta sobre a relação do fervor da figura mariana e a criação de um culto popular em sua honra. "Isso faz com que o patronato nacional mariano esteja frequentemente ligado a um imaginário muito rico, entretecido de aparições, milagres e prodígios vários” (BOFF, 2009, p. 304).

Nossa Senhora é um elemento na narrativa que gera desconforto. É nos informado que a Virgem está aparecendo uma localidade próxima a cidade de Eugene. A mariofania é um evento, que no contexto atual, não mexe apenas com a religiosidade católica. Movimenta tudo o que há ao redor, como turismo, comércio, jornalismo, por isso a precaução da Igreja 
Católica frente a esses acontecimentos.

Quando questionado sobre a veracidade das aparições, ele refuta por conta de a Igreja ainda não ter se posicionado. Amaka, sua sobrinha, diz: "além disso, já está mais do que na hora de Nossa Senhora aparecer na África. Você não acha estranho ela só aparecer na Europa? Afinal de contas ela era do Oriente Médio” (p. 148) Inclusive, Boff salienta o reduzido número de aparições marianas nos continentes africanos e asiáticos, sendo o maior número, quase que absoluto, em países europeus. $\mathrm{O}$ teólogo brasileiro entende que a mariofania possui um caráter libertador, por mexer principalmente com as camadas mais pobres da Igreja e se manifestar, na maioria das vezes, para pessoas pobres, muitas marginalizadas pela sociedade, como analfabetos. A liberdade surge, então, em os pobres se perceberem filhos queridos da Mãe de Deus e "na vertente propriamente 'carismática', livre ou informal da vida da Igreja, diferente da vertente 'institucional', hierárquica ou oficial” (BOFF, 2009, p. 553).

Nessa quase que inconcebível ideia da Virgem aparecer em solo africano por, talvez, a África e seu povo negro, não ser digno de tamanha graça, Kambili percebe que todas as vezes que ora, imagina um Deus branco com sotaque do Padre Benedict. Não há um aprofundamento dessa percepção, todavia é nítido que Chimamanda, em episódios constantes, critica esse ideário branco, uma certa colonização espiritual, que embranqueceu até mesmo Deus. Como diz Fanon: "quando mais assimilar os valores culturais da metrópole, mas o colonizado escapará da sua selva" (2008, p. 34).

\section{FALANDO COM NOSSOS ESPÍRITOS - ANTES DO DOMINGO DE RAMOS}

No segundo momento da narrativa somos transportados para um momento temporal antes de toda a confusão entre Papa e Jaja. A primeira menção a Deus vem da personagem da Mama, Beatrice, uma mulher resignada que não ousa se defender das violências que o marido a faz. Durante vários momentos da narrativa, Beatrice é descrita com hematomas no corpo, recuperações de abortos, silenciada frente a tudo isso. Mesmo sofrendo nas mãos do marido, Beatrice se resigna considerando-o um homem bom por suas filantropias e com momentos de raivas devido aos negócios.

A falsa harmonia familiar é desfeita com a chegada de um novo padre, Padre Amadi. Ele já traz um desconforto logo à primeira vista por ser negro. Além disso, insere durante a liturgia, músicas em igbo e aguça alegria na assembleia e descontração. O sacerdote nigeriano pratica um discurso religioso de agregação dos elementos étnicos, que mesmo inserido em uma religião ocidental, em forma de resistência, ainda traz em seu fazer sacerdotal os costumes característicos da sua sociedade tradicional. "É aqui que a mímica se apresenta como uma 'conciliação irônica', nos termos de Bhabha, retirando sua força de ambivalência entre o 'parecer igual' e o 'ser igual”' (REIS, 2011, p. 42).

Papa se exaspera com esse comportamento nada convencional.

- Aquele jovem padre cantando no meio do sermão como um homem sem Deus de uma dessas igrejas pentecostais que brotam em todos os cantos como cogumelos... Pessoas como ele trazem problemas para igreja. Precisamos nos lembrar de rezar por sua alma - disse Papa. (p. 35)

\footnotetext{
${ }^{6}$ De fato as aparições reconhecidas pela Igreja Católica são: 1846 e 1954 na França. 1917 em Portugal. 1961 na Espanha.
}

https://periodicos.unifap.br/index.php/letras

Macapá, v. 8, n. 3, $2^{\circ}$ sem., 2018 
Em seguida tem-se um dos momentos mais tensos da narrativa. Papa, depois da missa do Padre Amadi, quer visitar Padre Benedict e confabular sobre o comportamento do recém-chegado. Contudo, Mama não deseja sair do carro, visto que está grávida e sente enjoos. Papa enfurece-se. Ao chegar em casa, antes da refeição, Kambili descreve a prece paterna:

Quando Papa começou a oração, sua voz tremeu mais do que o normal. Ele agradeceu primeiro pela comida, depois pediu que Deus perdoasse aqueles que haviam tentado se opor à Sua vontade, que haviam colocado seus desejos egoístas em primeiro lugar e não quiseram visitar Seu servo após a missa. (p. 38)

Após o jantar depois que cada um foi para seu respectivo quarto, Kambili começa a escutar pancadas. Ela fecha os olhos e começa a contar. No número 19 de sua contagem, o silêncio volta. Automaticamente, os dois irmãos saem do quarto e se dirigem para a origem das pancadas. Não é descrito o estado em que encontram Mama, e sim o ágil serviço de limpeza que os filhos assumem, demonstrando o quão corriqueiro é aquilo a tal ponto deles já terem os papeis definidos: Kambili com o pano e Jaja com a escova. Mama é levada ao hospital e ao voltar informa que o bebê se foi.

Papa se alonga muitos em suas orações pelos ímpios e por seu país. "Papa rezou por vinte minutos pedindo que fôssemos protegidos, [...] pedindo pela Nigéria, [...] rezou pela conversão do nosso Papa-Nnukwu, para que ele pudesse ser salvo" (p. 68). É um profundo admirador da figura do seu sogro, um homem negro de pele clara - talvez albino. Sabedor de latim e das definições e dogmas do inconcluso Concílio Vaticano ${ }^{7}$, caiu nas graças dos missionários ingleses tornando-se o primeiro catequista da região. "Fazia as coisas do jeito certo, do jeito que os brancos fazem, não como o povo faz agora!” (p. 75).

Neste capítulo, temos a presença e a voz do avô paterno do Kambili, o homem pagão que o próprio filho rejeita. Ele professa a religião dos seus antepassados e mesmo que tenha dado seu filho para os ingleses educarem, ele próprio é resistente a cultura ocidental. Reis (2011) explica justamente como o próprio compatriota rural e não-cristão, será visto pelos demais como feiticeiro e perigoso. É a comparação que o negro, diz Fanon (2008), fará com seu semelhante em busca de se sentir superior e mais parecido com o europeu.

- Lembro do primeiro que apareceu em Abba, o que chamavam de Padi John. O rosto dele era
vermelho como dendê [...]. Â tarde, ele reunia as crianças debaixo da árvore de $u k w a$ que há na
missão e ensinavam sua religião a elas. Eu não me juntava a ele, kpa, mas às vezes ia ver o que
estavam fazendo. Um dia, perguntei: “Onde fica esse deus que vocês adoram?". Eles disseram
que o deus deles era como Chukwnu, que ele morava no céu. E eu perguntei: "Quem é essa
pessoa que foi morta, essa que fica pendurada na madeira do lado de fora da missão?". Eles
disseram que era o filho, mas que o filho e o pai eram iguais. Foi então que eu tive certeza de
que o branco era louco. O filho e o pai iguais? Tufia! Você não vê? É por isso que Eugene não
me respeita, porque pensa que somos iguais (p. 93).

Contraditório talvez seja a característica que mais define a personalidade de Eugene. Ao mesmo tempo que ele ralha com sua esposa que por, num gesto tradicional, ter se abaixado e permitido que o Igwe (espécie de governador tradicional) desse tapinhas, afirmando que não se deve se ajoelhar e prestar reverência para um ser humano, Eugene bate em Kambili, por ela, seguindo a lógica da explicação anterior, não ter se ajoelhado e beijado a

${ }^{7}$ O Concílio Vaticano I teve que ser interrompido em 1870 por causa da guerra franco-prussiana e a invasão de Roma. 
anel do bispo.

Ifeoma é a personagem que busca sincretizar, encontrar um meio termo entre o catolicismo e a religião tradicional. Ela é a ponte entre o irmão Eugene e o PapaNnukwu e até mesmo entre as separações rápidas de Eugene e Beatrice. Sua mente aberta a possibilidades espirituais são um choque para a mente conservadora dos irmãos Kambili e Jaja. As duas práticas religiosas não precisam necessariamente ser excludentes. O indivíduo híbrido, como elenca Hall (2003), tem essa "permissão" de entrelugar, de transitar concomitante entre várias esferas, pois o colonialismo derrubou barreiras mesmo ao impor sua cultura, e o mundo global, através do imperialismo, desconhece, cada vez mais culturas cristalizadas.

\footnotetext{
- Viu como seu Papa-Nnukwu está ficando bom? - Perguntou tia Ifeoma. - Faz bastante tempo que ele está sentado para Amaka poder pintar seu retrato. É um milagre. Nossa Senhora é fiel. - Como Nossa Senhora pode interceder por um pagão, tia?

Tia Ifeoma ficou em silêncio enquanto usava uma concha para colocar a pasta grossa de taioba dentro da panela de sopa; então me olhou e disse que Papa-Nnukwu não era um pagão, mas um tradicionalista, que às vezes o que era diferente era tão bom quanto o que era familiar, que quando Papa-Nnukwu fazia seu itu-nzu de manhã, sua declaração de inocência, era a mesma coisa do que quando rezávamos o rosário (p. 177).
}

No Pós-colonialismo, o hibridismo é entendido como trocas de influências culturais, "a qual subestimava a desigualdade inerente às relações de poder e enfatizava as políticas de assimilação através do mascaramento das diferenças culturais" (BONNICI, 2009, p. 30). Ligado ao termo mestiçagem, no sentido de fusão racial, o hibridismo também se associa ao termo sincretismo, que é a concomitância de credos religiosos. Cultura híbrida, no caso, é o encontro - porém, não fusão - de elementos oriundos de diferentes origens, que ao se aproximarem, criam novos objetos, práticas culturais.

É através da experiência religiosa de sua tia, que Kambili desconstruirá a visão preconceituosa que possui com as religiões tradicionais. Não atinge sua prática católica, mas influencia o seu irmão Jaja a resistir as práticas autoritárias do pai. Kambili está sempre em busca de agradar seu pai mesmo quando começa a enxergar a violência familiar em que está inserida. Seu irmão, ao contrário, à medida que toma consciência do ambiente agressivo em que está imerso - acadêmico, religioso e familiar - começa a se posicionar de maneira contrária aos gostos do pai, como no episódio da não comunhão.

\section{OS PEDAÇOS DE DEUSES - APÓS O DOMINGO DE RAMOS}

A frágil paz familiar começa a ruir. "Tudo desmoronou após o Domingo de Ramos" (p. 271). Jaja não sai mais do quarto e a saúde de Eugene vai se debilitando cada vez mais. O clima na casa é tenso. "Fui ficando apavorada à medida que o Domingo de Páscoa se aproximava" (p. 274). Kambili observa tudo como espectadora. Seu pai se debilitando a olhos visto, sua mãe aparentando uma sutil mudança frente ao autoritarismo do marido e Jaja se rebelando contra os desmandos do pai sobre a família. É sexta-feira santa e Papa, depois de derrubar o café, pois suas mãos estavam trêmulas, decide ir para missa só à noite. Kambili rememorara a missa da Paixão do ano anterior e seu pequeno teatro para agradar ao pai.

Achei a cruz fria quando a beijei. Um calafrio me percorreu e os pelos do meu braço se eriçaram.

https://periodicos.unifap.br/index.php/letras

Macapá, v. 8, n. 3, $2^{\circ}$ sem., 2018 
Quando já estávamos sentados, comecei a chorar em silêncio, deixando as lágrimas escorrerem pelas minhas bochechas. Muitas pessoas à minha volta também choraram, como faziam durante a Via Crúcis, em que gemiam e diziam: “Oh, veja o que o Senhor fez por mim” [...]. Papa ficou satisfeito com as minhas lágrimas. [...]. Embora eu não soubesse bem por que estava chorando, ou se estava chorando pelos mesmos motivos que aquelas pessoas que se ajoelhavam nos genuflexórios, fiquei orgulhosa quando Papa fez aquilo. (p. 274)

Amaka, filha da Tia Ifeoma, é uma personagem de resistência às práticas ocidentais, tal como o avô Papa Nnukwu. Em suas conversas com o Padre Amadi, Amaka questiona o fato do catolicismo da época negar a individualidade e a cultura dos africanos, indo contra a inculturação orientada pela constituição Gaudium et spes do Concílio Vaticano II. Exemplo é o fato que, ao se crismar, o jovem precisava escolher um nome inglês para poder receber o sacramento, visto que um nome africano não era aceito.

- Quando os missionários chegaram aqui, eles achavam que os nomes do povo igbo não eram
bons o suficiente. Insistiam para que as pessoas escolhessem um nome inglês antes de serem
batizadas. Nós não devíamos ter progredido? [...] - O que a Igreja está dizendo é que só um
nome inglês torna válida a nossa crisma. O nome "Chiamaka" diz que Deus é belo. "Chima"
diz que Deus sabe mais, "Chiebuka" diz que Deus é o melhor. Por acaso eles não glorificam
Deus da mesma forma que "Paul", "Peter" e "Simon"? (p. 286)

Depois argumenta sobre a ida do Padre Amadi para Alemanha em missão de evangelização, visto que na Europa diminuía cada vez mais o número de sacerdotes e era necessário agora importar padres. Amaka representa o outrora colonizado que questiona as imposições sociais, tal qual o objetivo do Pós-Colonialismo que visa a crítica e ampliação das vozes antes caladas. A menina domina a cultura do outro, que inquestionavelmente já é a sua, porém não se permite "engolir" sem antes questionar o porquê de assim ser.

- Os missionários brancos trouxeram seu deus para cá - disse Amaka. - Um deus da mesma cor que eles, adorado na língua deles e empacotado nas caixas que eles fabricam. Agora que estamos levando esse deus de volta para eles, não devíamos pelo menos empacota-lo em outra caixa. (p. 281)

\section{CONCLUSÃO}

A Nigéria, nos dias atuais, é alvo do grupo extremista islâmico Boko Haram, que sequestram meninas e as levam para seus acampamentos em lugares recônditos. As violentam, obrigam ao casório com adeptos do grupo ou as vendem no mercado de tráfico internacional de mulheres. Uma triste situação que tolhe a liberdade de meninas que muitas vezes são capturadas quando estão no ambiente escolar. Recentemente foi proibido por lei no país a clitorectomia. Essa prática religiosa, feita na insalubridade e sem anestesia, causadora de grande dor nas mulheres além de castrar suas sexualidades.

A autora Chimamanda ao permear toda a narrativa de Hibisco Roxo pela questão do confronto da religiosidade vivenciada por dois modos diferentes - tradicional e ocidental encontrou um ponto da sociedade pós-colonial para explorar o quanto a colonização desestabilizou as culturas das colônias. Hall é um importante estudioso que se debruçou sobre como a identidade do indivíduo moderno é construída e como resiste (ou não) frente a uma sociedade globalizada. Antes um sujeito unificado, hoje ele vive uma "crise de identidade" que abalou "os quadros de referências que davam aos indivíduos uma ancoragem estável 
no mundo social" (HALL, 2003, p. 7). Chimamanda em seu manifesto Para educar crianças feministas (2017), no conselho número 9 para sua amiga Ijeawele, aconselha sobre a importância de ensinar deste a tenra idade os filhos a terem orgulho de suas origens, justamente para aguçar o senso de identidade na criança. Entretanto, ela enfatiza a necessidade de ter uma criticidade aos elementos que são maléficos, como no caso da etnia igbo, a sujeição da mulher a vontade do homem e o materialismo em primeiro lugar na vida.

O mundo hoje é sincrético e global, quer queiram ou não os conservadores. Encontrar a paz através do ecumenismo é disseminar a desconstrução de preconceitos e autoritarismos, que atingiram, com esperança, o machismo, a prática patriarcal de o homem achar ser o dono da mulher. Obtendo isso, a religiosidade poderá ser experienciada de maneira plena sem distinção de gênero, classe, e o preceito universal - o amor ao próximo - poderá ser, sim, o centro e o objetivo da fé.

\section{REFERÊNCIAS}

ADICHIE, Chimamanda Ngozi. Hibisco Roxo. Trad. Julia Romeu. São Paulo: Companhia das Letras, 2011.

. Para educar crianças feministas: um manifesto. Trad. Denise Bottmann. São Paulo: Companhia das Letras, 2017.

BOFF, Clodovis M. Mariologia social: o significado da Virgem para a Sociedade. São Paulo: Paulus, 2006.

BONNICI, Thomas (org.). Resistência e intervenção nas literaturas pós-coloniais. Maringá: Eduem, 2009.

FANON. Frantz. Pele negra, máscaras brancas. Trad. Renato da Silveira. Salvador: EDUFBA, 2008.

HALL, S. A identidade cultural na pós - modernidade. Trad. Tomaz Tadeu da Silva, Guacira Lopes Louro.11. Ed. Rio de janeiro: DP\&A, 2003.

REIS, Eliana Lourenço de Lima. Pós-colonialismo, identidade e mestiçagem cultural: a literatura de Wole Soyinka. Belo Horizonte: Editora UFMG, 2011.

SAID, Edward W. Orientalismo: o Oriente como a invenção do Ocidente. Trada. Rosaura Eichenberg. São Paulo: Companhia das Letras, 2007.

SHOHAT, E; STAM, R. Crítica da imagem eurocêntrica: multiculturalismo e representação. Trad. Marcos Soares. São Paulo: Cosac Naify, 2006. 